\title{
Manajemen gulma di Kebun Kelapa Sawit Bangun Bandar: Analisis Vegetasi dan Seedbank Gulma
}

\author{
Weed Manajemen in Oil Palm Plantation of Bangun Bandar: Weespecies and Seedbank
}

\author{
Aditya Wira Tantra dan Edi Santosa*
}

Program Studi Agronomi dan Hortikultura, Fakultas Pertanian, Institut Pertanian Bogor (Bogor Agricultural University), Jl. Meranti Kampus IPB Dramaga, Bogor, 16680, Indonesia Telp. \& Faks. +62-251-8629353 e-mail agronipb@indo.net.id

*Penulis korespondensi: edisang@gmail.com

Disetujui 4 Mei 2016/ Published online 9 Mei 2016

\begin{abstract}
Weed management in oil palm plantation is one of important activities determined bunch production. Aim of current internship was to study weed management and factors determined the success of weed control. Internship was carried out in oil palm plantations of Bangun Bandar Farm, Medan, North Sumatra in Feb. to June 2015. Aspect of weed vegetation among palm plantation ages and its seedbank were evaluated during internship as special a topic. Result showed that generally, weed management had been conducted based on standard released by company. There were 39 weed species in the plantation, three of them, i.e., Ottochloa nodosa, Paspalum conjugatum, and Cyperus killingia analysis were dominant (SDR value > 10\%) High weed seedbank was found in young plantation (TBM) than other ages. TBM areas had 584 individuals $/ \mathrm{m}^{2}$, while young TM was 204 individuals $/ \mathrm{m}^{2}$ and old TM was 47 individuals $/ \mathrm{m}^{2}$ ). Dense weed seeds was found in 0-10 below soil. Overall weed seedbank were : broadleaf (199 individuals $\left./ \mathrm{m}^{2}\right)$, grass (74 individuals $/ \mathrm{m}^{2}$ ), and sedges (562 individuals $/ \mathrm{m}^{2}$ ).
\end{abstract}

Keywords: oil palm plantation, seedbank, weed

ABSTRAK

Manajemen gulma di kelapa sawit merupakan salah satu kegiatan penting yang menentukan keberhasilan produksi sawit. Kegiatan magang ini bertujuan untuk mengetahui bagaimana manajemen pengendalian gulma dilaksanakan dan aspek-aspek yang mempengaruhinya. Kegiatan magang dilaksanakan di kebun Bangun Bandar, Medan, Sumatera Utara, Februari- Juni 2015. Secara khusus, keragaan gulma pada berbagai umur tanaman dan simpanan biji gulma (seedbank) merupakan aspek khusus yang dikaji. Secara umum, kegiatan pengendalian gulma di kebun telah dilaksanakan dengan baik dan dikendalikan pada level di bawah ambang ekonomi. Dari analisis vegetasi diketahui bahwa dari 39 jenis gulma yang ada, empat jenis gulma yakni Ottochloa nodosa, Paspalum conjugatum, Muccuna Bracteata, dan Cyperus killingia merupakan gulma paling dominan dengan nilai SDR di atas $10 \%$. Terdapat variasi seedbank antara lahan TBM, TM muda dan TM tua. Pada areal TBM densitas simpanan biji gulmanya lebih tinggi (584 individu/ $\mathrm{m}^{2}$ ) dibandingkan dengan areal TM muda (204 individu $\left./ \mathrm{m}^{2}\right)$ dan TM tua (47 individu $/ \mathrm{m}^{2}$ ). Seedbank terbanyak diperoleh 0-10 cm. Secara keseluruhan, seedbank yang berhasil tumbuh: daun lebar $\left(199\right.$ individu $\left./ \mathrm{m}^{2}\right)$, rumput (74 individu $\left./ \mathrm{m}^{2}\right)$, paku-pakuan $\left(0\right.$ individu $\left./ \mathrm{m}^{2}\right)$, dan teki $\left(562\right.$ individu $\left./ \mathrm{m}^{2}\right)$.

Kata kunci: gulma, kelapa sawit, simpanan biji gulma 


\section{PENDAHULUAN}

Tanaman kelapa sawit (Elaeis guineensis Jacq) telah dibudidayakan di Indonesia sejak 1848, dan mulai dibudidaya secara komersil dalam bentuk perusahaan perkebunan pada tahun 1911 . Pada saat ini, kelapa sawit telah menyebar disebagian besar wilayah Indonesia dan menjadi penggerak pertumbuhan dan ekonomi wilayah.

Keberhasilan budidaya kelapa sawit ditentukan oleh keberhasilan dalam mengendalikan faktor produksi. Pada umumnya, faktor produksi ditentukan oleh interaksi antara genetik, lingkungan dan teknologi budidaya yang digunakan. Pengendalian faktor genetik tanaman cukup jelas yakni dipengaruhi oleh kualitas bibit, kemurnian genetik, dan potensi produksi yang ada. Terdapat dua faktor lingkungan yang penting yakni faktor tanah dan faktor iklim. Teknologi budidaya meliputi proses penanaman, pemeliharaan hingga panen. Keberhasilan dalam mengendalikan faktor-faktor tersebut akan menentukan keberhasilan budidaya tanaman.

Pengendalian gulma adalah salah satu dari kegiatan pemeliharaan dalam budidaya kelapa sawit. Menurut Direktur Jendral Perkebunan tahun (2013), gulma pada tanaman kelapa sawit dapat menurunkan produktivitas, seperti pada gulma Mikania micrantha dapat menurunkan produksi TBS sebesar $20 \%$. Dinamika gulma yang ada pada kelapa sawit dipengaruhi oleh banyak faktor diantaranya adalah umur tanaman, jenis tanah, teknologi pengendalian yang digunakan, faktor iklim dan keberadaan seedbank. Faktor-faktor tersebut selain mempengaruhi dinamika gulma juga akan menentukan tingkat keberhasilan atau efektivitas dalam kegiatan pengendalian. Penelitian pada tanaman kelapa sawit di Jambi menunjukkan bahwa komposisi gulma terdiri 20 famili, 47 genus, 56 spesies, dan 3934 individu (Adriadi et al.,2012).

Menurut Pahan (2008), secara umum kegiatan pengendalian gulma dilakukan secara manual, secara kimia dan secara kultur teknis. Pengendalian gulma manual adalah menggunakan alat cangkul dan sebagainya, sedangkan pengendalian secara kimia adalah menggunakan herbisida. Herbisida yang digunakan ada yang bersifat kontak dan ada yang bersifat sistemik. Selain itu, ada herbisida yang memiliki spektrum luas dan spektrum sempit. Pengendalian gulma secara kultur teknis antara lain dengan menanam LCC atau memelihara keberadaan serangga pemakan gulma. Namun demikian, strategi yang digunakan dalam kegiatan pengendalian dapat berbeda-beda antar kebun (spasial) dan antar waktu (temporal). Oleh karena itu, penting untuk dikaji bagaimana pemilihan kegiatan pengendalian gulma tersebut dilakukan.

Seedbank gulma adalah simpanan biji gulma atau propagul yang ada dalam tanah, dan ketika faktor pertumbuhan memungkinkan akan berkembang menjadi individu gulma. Keberadaan seedbank gulma dapat diketahui dengan cara melihat adanya individu gulma yang tumbuh kembali (regrowth) setelah dilakukan kegiatan pengendalian gulma. Pada kegiatan magang ini, seedbank gulma yang ada di berbagai kedalaman tanah akan diamati sebagai aspek khusus. Tujuan kegiatan magang yang dilakukan adalah untuk mempelajari, memperoleh pengalaman dan keterampilan kerja pada aspek pengendalian gulma di perkebunan kelapa sawit. Secara khusus diamati efektivitas kegiatan pengendalian gulma kaitannya dengan seedbank gulma.

\section{BAHAN DAN METODE}

Pelaksanaan magang dilaksanakan pada tanggal 09 Februari sampai dengan 08 Juni 2015 di Perkebunan Kelapa Sawit Bangun Bandar, Medan, Sumatera Utara. Kegiatan magang dilaksanakan selama 4 bulan. Kegiatan magang pada bulan pertama adalah mengumpulkan data sekunder kebun dan menjadi pendamping mandor. Pengumpulan data sekunder kebun dilakukan di kantor besar Bangun Bandar. Kegiatan selama menjadi pendamping mandor adalah mengawasi pekerjaan karyawan di lapangan serta membuat laporan kerja harian. Kegiatan magang pada bulan kedua adalah menjadi pendamping asisten dan melakukan pembuatan herbarium, administrasi, serta pengambilan sampel gulma secara khusus. Kegiatan yang dilaksanakan selama menjadi pendamping asisten adalah melakukan pengecekan pekerjaan karyawan, serta melakukan administrasi di Kantor Divisi. Kegiatan magang pada bulan ketiga dan keempat adalah menjadi Buruh Harian Lepas (BHL). Penulis juga melakukan observasi ke pabrik dan melakukan ekstraksi buah di laboratorium pabrik.

Selama kegiatan magang, penulis juga melakukan kegiatan pengataman khusus terkait pengelolaan gulma. Pengumpulan data terkait pengendalian gulma dilakukan dengan melakukan percobaan, dan pengumpulan data lain melalui pengamatan lapangan, wawancara dengan petugas yang ada, serta data arsip kebun.

Pengumpulan data primer saat magang meliputi data pengendalian gulma dan data seedbank. Data gulma pertama adalah analisis vegetasi gulma yang diperoleh dengan cara analisis kuandran ukuran $50 \mathrm{~cm} \times 50 \mathrm{~cm}$ pada 
seluruh blok di afdeling 1 kebun Bangun Bandar. Data kedua adalah data seedbank gulma.

Seedbank gulma diamati pada TBM, TM muda dan TM tua. Tanah dari umur tanam tersebut digali dan diambil ukuran panjang-lebar-dalam 20 $\mathrm{cm}$ x $20 \mathrm{~cm}$ x $10 \mathrm{~cm}$. Kedalaman $10 \mathrm{~cm}$ pertama diletakkan pada tray plastic A, lalu $10 \mathrm{~cm}$ kedua diletakkan pada Tray $\mathrm{B}$ dan $10 \mathrm{~cm}$ ketiga diletakkan pada tray C. Setiap umur tanaman diulang 3 kali. Gulma yang tumbuh lalu diamati jenis dan jumlahnya. Jumlah gulma yang muncul dihitung sebagai jumlah seed bank untuk species tertentu.

Analisis yang dilakukan untuk mengolah data gulma tersebut adalah dengan cara analisis kualitatif dan kuantitatif. Analisis kualitatif dilakukan dengan cara melakukan pengamatan terhadap kematian dan pertumbuhan kembali. Analisis kuantitatif yang dilakukan adalah dengan menggunakan matematika sederhana seperti ratarata dan persentase. Analisis tersebut digunakan untuk menghitung perbandingan target dan realisasi pengendalian gulma secara kimia dan mekanis. Perhitungan yang digunakan untuk menganalisis vegetasi gulma yang tumbuh dominan menggunakan summed dominance ratio (SDR) (Moenadir, 1993). Nilai SDR menunjukan dominansi suatu gulma yang tumbuh di perkebunan kelapa sawit. Jika nilai SDR suatu gulma tinggi, maka dominansi gulma tersebut tinggi. Begitupun sebaliknya, jika nilai SDR suatu gulma rendah, maka dominansinya rendah. Perhitungan nilai penting dan penentuan SDR dilakukan dengan rumus berikut.

$\begin{aligned} \mathrm{KN} & =\frac{\text { Kerapatan jenis gulma }}{\text { Kerapatan mutlak semua jenis gulma }} \\ \mathrm{FN} & =\frac{\text { Frekuensi jenis gulma }}{\text { Frekuensi mutlak semua jenis gulma }} \\ \mathrm{NP} & =\mathrm{KN}+\mathrm{FN} \\ \mathrm{SDR} & =\frac{\mathrm{NP}}{2}\end{aligned}$

Keterangan: KN: Kerapatan Nisbi, FN: Frekuensi Nisbi, NP: Nilai Penting

\section{HASIL DAN PEMBAHASAN}

\section{Analisis Vegetasi Gulma Metode Kuadran}

Analisis vegetasi dilaksanakan pada tanggal 30 Maret - 1 Mei 2015 menggunakan alat kuadran berukuran $50 \mathrm{~cm}$ x $50 \mathrm{~cm}$. Pengamatan dilakukan di semua blok afdeling 1 Kebun Bangun Bandar yang berjumlah 23 blok pada semua kategori tanaman TBM, TM Muda dan TM Tua. Sampel diambil sebanyak 8 titik untuk blok dengan kategori tanaman hanya satu (TM) atau blok yang masih belum ditanam, dan 16 titik untuk blok yang memiliki dua kategori tanaman (TBM dan TM). Sehingga jumlah titik lemparan kuadran sebanyak 208 titik yang tersebar pada 23 blok. Setiap titik lemparan diamati jenis-jenis gulmanya dan dihitung banyak gulma secara manual.

Perhitungan yang digunakan untuk menganalisis vegetasi gulma yang tumbuh dominan menggunakan summed dominance ratio (SDR) (Moenadir, 1993) yang dapat menggambarkan dominansi gulma pada suatu areal tertentu dalam menguasai sarana tumbuh yang didapatkan dari besaran kerapatan mutlak $(\mathrm{KM})$, frekuensi mutlak (FM), kerapatan nisbi $(\mathrm{KN})$, frekuensi nisbi (FN), dan nilai penting (NP). Kerapatan dihitung dengan satuan individu. Nilai SDR menunjukan dominansi suatu gulma yang tumbuh di perkebunan kelapa sawit Bangun Bandar. Jika nilai SDR suatu gulma tinggi, maka dominansi gulma tersebut tinggi. Begitupun sebaliknya, jika nilai SDR suatu gulma rendah, maka dominansinya rendah.

Nilai SDR pada masing-masing individu gulma menunjukkan bahwa gulma tersebut menguasai sebanyak persen sarana tumbuh yang ada. Secara umum gulma yang menguasai areal Kebun Bangun bandar di afdeling 1 adalah golongan rumput Ottochloa nodosa, golongan teki Cyperus killingia, serta golongan daun lebar pada lahan TBM Muccuna Bracteata, dan pada lahan TM Muda dan TM Tua yaitu Ageratum conyzoides (Tabel 1).

\section{Simpanan Biji Gulma (Seedbank)}

Hasil perhitungan terhadap pertumbuhan individu gulma pada lahan yang berbeda umur dan kedalamannya menunjukkan adanya perbedaan banyaknya simpanan biji gulma (densitas seedbank gulma). Densitas seedbank gulma dapat dilihat pada Tabel 2.

Tabel 2 menunjukkan bahwa simpanan biji gulma secara kesuluruhan lebih banyak pada lahan kelapa sawit TBM yaitu 584 individu $/ \mathrm{m}^{2}$ berbanding jauh dengan jumlah simpanan biji gulma pada lahan kelapa sawit TM Muda yang tidak mencapai setengah dari jumlah simpanan biji gulma di TBM yaitu sebanyak 204 individu/m². Jumlah seedbank yang dihasilkan pada lahan kelapa sawit TM Tua sebanyak 47 individu/ $\mathrm{m}^{2}$. Perbedaan yang terjadi pada umur tanaman kelapa sawit karena persaingan untuk tumbuh pada lahan baru sangat kecil bagi gulma sehingga gulma tumbuh dengan sangat mudah. Penggunaan herbisida gramoxone sangat tepat dalam pengendalian gulma tersebut. Namun, penggunaan herbisida tersebut hanya 
bekerja pada permukaan tanah, simpanan biji gulma di dalam tanah tidak ikut terhambat secara

Tabel 1. Dominansi Gulma di Afdeling 1 di Kebun Bangun Bandar

\begin{tabular}{|c|c|c|}
\hline Nama gulma & Jenis gulma & SDR $(\%)$ \\
\hline \multicolumn{3}{|c|}{ Tanaman belum menghasilkan } \\
\hline Ottochloa nodosa & Rumput & 18.75 \\
\hline Muccuna Bracteata & Daun Lebar & 16.03 \\
\hline Panicum Sp. & Rumput & 10.8 \\
\hline Eleusine indica & Rumput & 8.91 \\
\hline Paspalum conjugatum & Rumput & 8.71 \\
\hline Cyperus killingia & Teki & 8.68 \\
\hline Stenotaphrum secundatum & Rumput & 8.05 \\
\hline Cleome rutidosperma & Daun Lebar & 4.47 \\
\hline Ageratum conyzoides & Daun Lebar & 2.52 \\
\hline Dactyloctenium aegypthum & Rumput & 2.4 \\
\hline Nephrolepis bisserata & Pakis & 1.95 \\
\hline Displazium esculentum & Pakis & 1.95 \\
\hline Axonopus comperssus & Rumput & 1.83 \\
\hline Euphorbia hirta & Daun Lebar & 1.72 \\
\hline Oldenlandia corymbosa & Daun Lebar & 1.61 \\
\hline Setaria plicata & Rumput & 1.49 \\
\hline \multicolumn{3}{|c|}{ Tanaman menghasilkan muda } \\
\hline Ottochloa nodosa & Rumput & 14.50 \\
\hline Cyperus killingia & Teki & 12.01 \\
\hline Paspalum conjugatum & Rumput & 11.19 \\
\hline Eleusine indica & Rumput & 6.63 \\
\hline Ageratum conyzoides & Daun Lebar & 6.13 \\
\hline Peperomia pellucida & Daun Lebar & 5.00 \\
\hline Stenotaphrum secundatum & Rumput & 4.71 \\
\hline Nephrolepis bisserata & Pakis & 4.05 \\
\hline Curculigo villosa & Daun Lebar & 3.46 \\
\hline Setaria plicata & Rumput & 3.25 \\
\hline Clidemia hirta & Daun Lebar & 3.21 \\
\hline Panicum Sp. & Rumput & 3.17 \\
\hline Muccuna Bracteata & Daun Lebar & 2.59 \\
\hline Digitaria adscendens & Rumput & 2.33 \\
\hline Axonopus comperssus & Rumput & 2.24 \\
\hline Displazium esculentum & Pakis & 2.17 \\
\hline Mikania micrantha & Daun Lebar & 2.00 \\
\hline Pteredium Sp. & Pakis & 1.87 \\
\hline Euphorbia hirta & Daun Lebar & 1.83 \\
\hline Colocasia Sp. & Daun Lebar & 1.48 \\
\hline Melastoma malabatrichum & Daun Lebar & 1.24 \\
\hline
\end{tabular}

Pertumbuhan individu gulma pada lahan TM muda dan TM tua lebih kecil dari lahan TBM karena persaingan tumbuh bagi gulma dengan pokok kelapa sawit sangat besar, sehingga simpanan biji gulma di dalam tanah lebih susah untuk berkembang. Pengendalian gulma pada TM muda biasanya menggunakan herbisida jenis roundup dan dacomin sedangkan TM tua menggunakan herbisida jenis roundup dan starane.

Perbedaan jumlah simpanan biji gulma di dalam tanah terhadap kedalaman tanah juga terlihat pada tabel 2. Gulma jenis daun lebar pada kedalaman $0 \mathrm{~cm}-10 \mathrm{~cm}$ di lahan kelapa sawit keseluruhan. Sehingga masih tingginya densitas seedbank gulma pada lahan kelapa sawit TBM.

Tabel 1. Lanjutan...

\begin{tabular}{|c|c|c|}
\hline Nama Gulma & Jenis Gulma & SDR (\%) \\
\hline \multicolumn{3}{|c|}{ Tanaman menghasilkan muda } \\
\hline Cleome rutidosperma & Daun Lebar & 1.01 \\
\hline Colopogonium тисипоides & Daun Lebar & 0.96 \\
\hline Asystasia gangetica & Daun Lebar & 0.66 \\
\hline Borreria alata & Daun Lebar & 0.62 \\
\hline Cyperus cyperoides & Teki & 0.43 \\
\hline Phyllanthus niruri & Daun Lebar & 0.40 \\
\hline Stenochlaena palustris & Rumput & 0.40 \\
\hline Solanum Sp. & Daun Lebar & 0.38 \\
\hline \multicolumn{3}{|c|}{ Tanaman menghasilkan tua } \\
\hline Ottochloa nodosa & Rumput & 18.88 \\
\hline Paspalum conjugatum & Rumput & 9.38 \\
\hline Ageratum conyzoides & Daun Lebar & 7.22 \\
\hline Stenotaphrum secundatum & Rumput & 6.77 \\
\hline Nephrolepis bisserata & Pakis & 6.38 \\
\hline Colopogonium тисипоides & Daun Lebar & 5.95 \\
\hline Cyperus killingia & Teki & 5.51 \\
\hline Clidemia hirta & Daun Lebar & 3.77 \\
\hline Panicum Sp. & Rumput & 3.69 \\
\hline Axonopus comperssus & Rumput & 3.59 \\
\hline Displazium esculentum & Pakis & 3.37 \\
\hline Setaria plicata & Rumput & 2.63 \\
\hline Phyllanthus niruri & Daun Lebar & 2.54 \\
\hline Curculigo villosa & Daun Lebar & 2.47 \\
\hline Mimosa invisa & Daun Lebar & 2.22 \\
\hline Euphorbia hirta & Daun Lebar & 2.14 \\
\hline Peperomia pellucida & Daun Lebar & 2.14 \\
\hline Melastoma malabatrichum & Daun Lebar & 2.06 \\
\hline Mikania micrantha & Daun Lebar & 1.22 \\
\hline Selaginella willdenowii & Pakis & 1.22 \\
\hline Colocasia Sp. & Daun Lebar & 1.02 \\
\hline Eleusine indica & Rumput & 0.98 \\
\hline Chantella asiatica & Daun Lebar & 0.76 \\
\hline Drimaria cordata & Daun Lebar & 0.76 \\
\hline Pteris Sp. & Pakis & 0.73 \\
\hline Caladium bicolor & Daun Lebar & 0.53 \\
\hline Euphorbia prunifolia & Daun Lebar & 0.53 \\
\hline Pteredium $S p$. & Pakis & 0.53 \\
\hline Borreria alata & Daun Lebar & 0.46 \\
\hline Digitaria adscendens & Rumput & 0.46 \\
\hline
\end{tabular}

Sumber : Hasil pengamatan penulis di lapangan

TBM sebanyak 30 individu $/ \mathrm{m}^{2}$. Terjadi penurunan pada kedalaman $10 \mathrm{~cm}-20 \mathrm{~cm}$ sebanyak 4 individu. Dan kembali terjadi penurunan pada kedalaman $20 \mathrm{~cm}-30 \mathrm{~cm}$ sebanyak 7 individu. Hal ini menunjukkan semakin dalam kedalaman tanah maka jumlah individu biji gulma semakin berkurang. Terjadi perbedaan pada lahan TM muda yaitu pada kedalaman $10 \mathrm{~cm}-20 \mathrm{~cm}$ jumlah individu biji gulma lebih banyak 15 individu gulma daripada di kedalaman $0 \mathrm{~cm}-10 \mathrm{~cm}$. Kemungkinan terjadinya karena adanya legume penutup tanah (LCC) yang dapat menghambat perkecambahan gulma melalui penutupannya 
sehingga seedbank gulma tertahan pada kedalaman $10 \mathrm{~cm}-20 \mathrm{~cm}$. Secara keseluruhan jumlah simpanan biji gulma lebih banyak terakumulasi pada permukaan tanah hingga kedalaman $10 \mathrm{~cm}$. Untuk jumlah simpanan biji gulma jenis rumput dan teki pada lahan TBM lebih banyak individunya pada kedalaman $10 \mathrm{~cm}-20 \mathrm{~cm}$, berbeda dengan lahan TM muda lebih banyak pada kedalaman $20 \mathrm{~cm}-30 \mathrm{~cm}$ walaupun dalam jumlah perbedaan yang sedikit, pada lahan TM Tua secara keseluruhan jumlah individu gulmanya merata. Gulma jenis teki mendominasi pertumbuhan biji gulma dalam tanah yaitu sebanyak 562 individu $/ \mathrm{m}^{2}$, diikuti dengan gulma jenis daun lebar sebanyak 199 individu/m², kemudian gulma jenis rumput sebanyak 74 individu $/ \mathrm{m}^{2}$. Sementara, gulma jenis paku tidak ditemukan pertumbuhannya.

Tabel 2. Data Pengamatan Seedbank Gulma (Simpanan Biji Gulma dalam Tanah) di Divisi I, Kebun Bangun Bandar

\begin{tabular}{|c|c|c|c|c|c|}
\hline \multirow{2}{*}{ Lahan } & \multicolumn{4}{|c|}{ Densitas seedbank ( Jumlah individu $/ \mathrm{m}^{2}$ ) } & \multirow{2}{*}{ Total } \\
\hline & Daun lebar & Rumput & Paku & Teki & \\
\hline \multicolumn{6}{|l|}{ TBM } \\
\hline $0 \mathrm{~cm}-10 \mathrm{~cm}$ & 50 & 17 & 0 & 141 & 208 \\
\hline $10 \mathrm{~cm}-20 \mathrm{~cm}$ & 46 & 22 & 0 & 163 & 231 \\
\hline $20 \mathrm{~cm}-30 \mathrm{~cm}$ & 39 & 11 & 0 & 95 & $\begin{array}{l}145 \\
\mathbf{5 8 4}\end{array}$ \\
\hline \multicolumn{6}{|l|}{ TM Muda } \\
\hline $0 \mathrm{~cm}-10 \mathrm{~cm}$ & 12 & 5 & 0 & 46 & 63 \\
\hline $10 \mathrm{~cm}-20 \mathrm{~cm}$ & 27 & 3 & 0 & 42 & 72 \\
\hline $20 \mathrm{~cm}-30 \mathrm{~cm}$ & 10 & 6 & 0 & 53 & $\begin{array}{c}69 \\
204\end{array}$ \\
\hline \multicolumn{6}{|l|}{ TM Tua } \\
\hline $0 \mathrm{~cm}-10 \mathrm{~cm}$ & 7 & 3 & 0 & 7 & 17 \\
\hline $10 \mathrm{~cm}-20 \mathrm{~cm}$ & 5 & 4 & 0 & 6 & 15 \\
\hline $20 \mathrm{~cm}-30 \mathrm{~cm}$ & 3 & 3 & 0 & 9 & 15 \\
\hline
\end{tabular}

\section{KESIMPULAN}

Lahan kelapa sawit di TBM menunjukkan densitas simpanan biji gulma dalam tanah yang lebih tinggi $\left(584\right.$ individu $\left./ \mathrm{m}^{2}\right)$ dibandingkan dengan lahan kelapa sawit di TM muda (204 individu $\left./ \mathrm{m}^{2}\right)$ dan TM tua (47 individu $\left./ \mathrm{m}^{2}\right)$. Densitas simpanan biji gulma dalam tanah terbanyak pada permukaan tanah hingga kedalaman $10 \mathrm{~cm}$. Seedbank gulma pada lahan kelapa sawit di terdiri dari gulma daun lebar (135 individu $/ \mathrm{m}^{2}$ ), gulma rumput (50 individu $/ \mathrm{m}^{2}$ ), dan gulma teki (399 individu/ $\mathrm{m}^{2}$ ). Seedbank gulma pada lahan kelapa sawit di TM muda terdiri dari gulma daun lebar (49 individu $/ \mathrm{m}^{2}$ ), gulma rumput (14 individu $\left./ \mathrm{m}^{2}\right)$, dan gulma teki (141 individu $/ \mathrm{m}^{2}$ ). Sementara, pada lahan kelapa sawit di TM tua terdiri dari gulma daun lebar (15 individu $\left./ \mathrm{m}^{2}\right)$, gulma rumput $\left(10 \mathrm{individu} / \mathrm{m}^{2}\right)$ dan gulma teki (22 individu/ $\mathrm{m}^{2}$ ). Gulma jenis paku tidak terdapat di semua jenis lahan kelapa sawit.

\section{DAFTAR PUSTAKA}

Adriadi, A., Chairul dan Solfiyeni. 2012. Analisis Vegetasi Gulma pada Perkebunan Kelapa Sawit (Elaeis guineensis Jacq.) di Kilangan, Muaro Bulian, Batang
Hari. Jurnal Biologi Universitas Andalas 1(2): 108-115

Arsyad, A,R. 2012. Pemupukan Kelapa Sawit Berdasarkan Potensi Produksi Untuk Meningkatkan Hasil Tandan Buah Segar (Tbs) Pada Lahan Marginal Kumpeh. Penelitian Universitas Jambi Seri Sains 14 (1): 29-36.

Barus, E. 2003. Pengendalian Gulma di Perkebunan, Efektivitas dan Efisiensi Aplikasi Herbisida. Yogyakarta (ID) : Kanisius.

Gusniawati, et al. 2012. Kelapa Sawit (Elais Guineensis Jaqc. ) di Pembibitan Utama dengan Perbedaan Kombinasi Pupuk Cair Nutrifarm dan Npkmg. Agroteknologi 1 (1): 46-55.

Kusno, A., Nurjaya. 2011. Pengaruh Pupuk Kiserit Terhadap Pertumbuhan Kelapa Sawit dan Produktivitas Tanah. Littri 17(4) : 133-139.

Lumbangaol, P. 2008. Rekomendasi Pupuk Kelapa Sawit. Sumatra (ID) : Rekomendasi kelapa sawit. 
Luz, P.B. et al. 2008. Effect of foliar and substrate fertilization on lady palm seedling growth and development. Journal of Plant Nutrition (31): 1311-1318.

Maryani, A.T. 2012. Pengaruh Volume Pemberian Air Terhadap Pertumbuhan Bibit Kelapa Sawit Di Pembibitan Utama. Agroteknologi 1 (2): 64-75.

Moenandir, J. 1993. Ilmu Gulma. Raja Grafindo Persada. 181 hal.

Pahan, I. 2013. Panduan Lengkap Kelapa Sawit Manajemen Agribisnis dari Hulu hingga Hilir. Jakarta (ID): Penebar Swadaya.
Risza, S. 1994. Kelapa Sawit, Upaya Peningkatan Produktivitas. Yogyakarta (ID) : Kanisius.

Risza, S. 2010. Masa Depan Perkebunan Kelapa Sawit Indonesia. Yogyakarta (ID) : Kanisius.

Sastrosayono, S. 2007. Budi Daya Kelapa Sawit. Jakarta (ID) : Agromedia Pustaka.

Sembiring, E.L. 2013. Pengaruh Penggunaan Pupuk Kascing Terhadap Pertumbuhan Bibit Kelapa Sawit (Elaeis Guineensis Jacq.) Dari Berbagai Sumber Asal Bibit di Pembibitan Utama. Agroteknologi 1(1) : 1-13.

Sudarmo, 2001. Pengendalian Serangga, Hama Penyakit, dan Gulma Padi. Penerbit Kanisius 